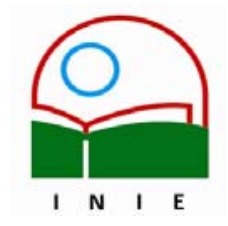

Universidad de Costa Rica

Facultad de Educación

Instituto de Investigación en Educación

ACTUALIDADES INVESTIGATIVAS EN EDUCACION

\title{
INTERACCIONES PERSONALES ENTRE DOCENTES Y ESTUDIANTES EN EL PROCESO DE ENSEÑANZA Y APRENDIZAJE
}

\author{
Un estudio de caso
}

\begin{abstract}
Jenny María Artavia Granados ${ }^{1}$
Resumen: Este artículo considera los resultados de un estudio de caso, que muestra las interacciones personales que se suscitan cotidianamente, en el proceso de enseñanza y aprendizaje que una docente y sus estudiantes de primer grado, comparten en el salón de clases.

Como elementos del estudio, se tomaron en cuenta el tipo de relación afectiva, el nivel de participación, así como el tipo de comunicación verbal y no verbal que fomenta la docente en la relación con los estudiantes. Por último, se presenta una serie de conclusiones que permiten reflexionar acerca de aquellos aspectos que podrían resultar precisos para desarrollar los procesos educativos armoniosos y comunicativos.
\end{abstract}

Palabras claves: INTERACCIONES PERSONALES/ RELACIONES AFECTIVAS DOCENTE Y ESTUDIANTES/ COMUNICACIÓN VERBAL Y NO VERBAL EN EL AULA/ TACTO PEDAGÓGICO/ PROCESO DE ENSEÑANZA Y APRENDIZAJE/

\begin{abstract}
This article contains a brief analysis of the personal interrelations that are provoked daily, in the process of teaching and learning that sahare in the hall class, a professor and her students in first degree.

As elements of the study, they were taken into account the type of affective relation, the participation level, as well as the type of verbal and nonverbal communication that foments the professor in the relation with the students. Finally, it offers a series of conclusions that allows us to reflect about those aspects that, they could be precise to develop harmonious and communicative educative processes.
\end{abstract}

Keys words: PERSONAL NTERACTIONS/ PROCESS OF EDUCATION AND LEARNING/ VERBAL AND NONVERBAL COMMUNICATION IN THE CLASSROOM PEDAGOGICAL TACT/ EDUCATIONAL AFFECTIVE RELATIONS AND STUDENTS/

\section{1- Primera parte}

\section{Introducción}

En el proceso de enseñanza y aprendizaje que se lleva a cabo en los salones de clase de educación primaria, se presentan interacciones sociales que son producto, tanto de la influencia recíproca entre el docente y sus estudiantes, como entre los mismos estudiantes.

\footnotetext{
1 Máster en Psicopedagogía de la Universidad Estatal a Distancia, Costa Rica. Licenciada en Educación Primaria y en Administración Educativa de la Universidad de Costa Rica. Docente del Departamento de Ciencias de la Educación, Coordinadora del Programa de Investigación "La Educación y sus perspectivas en la región Occidente", en la Sede de Occidente de la Universidad de Costa Rica.
}

Correo electrónico: artaviagi@hotmail.com

Artículo recibido: 20 de octubre, 2005

Aprobado: 12 de diciembre, 2005 
Cuando el docente y su grupo de estudiantes participan cotidianamente en los mismos procesos educativos, comparten sentimientos y experiencias de su entorno. Estos aspectos resultan medulares en el desarrollo integral de cada persona y lo preparan para desarrollarse socialmente.

En las relaciones que se suscitan cotidianamente en los salones de clase, como lo señalan Vásquez y Martínez (1996), el sistema educativo mismo predetermina las funciones que, tanto el docente como el estudiante, deberán asumir en los contactos interpersonales que se producen en el medio escolar. Así, al docente se le otorga el "poder vertical", el cual reconoce la autoridad para decidir sobre las actuaciones que se van a suscitar con la y el estudiante. Por otra parte, al estudiante se le posibilita relacionarse horizontalmente con sus pares, cuyas relaciones estarán decididas o supervisadas por el docente.

Desde esta visión, el profesional en el área de la educación, puede reflexionar acerca de la necesidad de flexibilizar el desempeño de su labor, pues esto le permitirá tener mayor contacto con las y los estudiantes para lograr relaciones impregnadas de mayor afecto, seguridad y comprensión hacia ellos y ellas. Estos sentimientos van a motivar que en el salón de clase, reine un ambiente, que, además de ser apto para el aprendizaje, sea para sí mismo y las y los educandos, un lugar de sana convivencia.

Ante la necesidad que reviste el desarrollo armonioso entre los sujetos en el salón de clases, se consideró, mediante un estudio de caso, analizar las interacciones personales que se susciten entre la docente $G$ y sus estudiantes de un primer grado de la Escuela El Geranio de la Dirección Regional de Educación de San Ramón. Para alcanzar dicho objetivo, se tomaron en cuenta las siguientes categorías:

- el tipo de relación afectiva que se manifiesta entre la docente y sus estudiantes. Para efectos de este estudio se entenderá por relación afectiva docente- estudiantes, aquel tipo de empatía que se da entre ambos y que puede ser expresada a través de relaciones caracterizadas por afecto, seguridad y comprensión.

- el tipo de comunicación verbal y no verbal empleada por la docente en su relación con las y los niños.

Referido a la forma en que la docente se comunica con las y los estudiantes, ésta puede tomar en cuenta el lenguaje verbal (tono de voz, las palabras que utiliza para llamar la atención o simplemente para referirse a ellos) y el lenguaje no verbal (gestos, señales, etc). 
- el nivel de participación que fomenta la docente con las y los estudiantes.

Entendido como el grado de participación que fomenta la docente con las y los estudiantes, a través de actividades escolares que susciten el intercambio frecuente de conocimientos y experiencias previas, que enriquezcan el proceso y aprendizaje que se desarrolla en el salón de clases.

Para desarrollar de manera objetiva los aspectos anteriores, fue necesario, mediante la observación en el aula, conocer la interacción cotidiana entre la docente y las y los niños al desarrollar los diferentes procesos de enseñanza y aprendizaje. Para ello, se llevaron a cabo diez observaciones no participantes y la información se registró empleando una bitácora por lección observada. Además, se entrevistó tanto a la docente, como a las y los estudiantes, con el fin de recolectar la información precisa para luego iniciar el proceso de análisis respectivo.

La escuela elegida para el estudio, se denominó como Escuela El Geranio; a la docente se le identificó con una letra del abecedario $(G)$ y a la población estudiantil únicamente por un nombre, con el fin de garantizar la confidencialidad de los datos.

Este artículo está conformado por dos partes; en primera instancia, se presenta el apartado "El tacto pedagógico en las relaciones entre el docente y los estudiantes", el cual hace referencia al tipo de relaciones personales que se suscitan entre los docentes y los estudiantes, en los salones de clase. El segundo apartado denominado "El tacto pedagógico en un salón de clases. Caso específico: la sala de clases de la docente G", en el cual se presentan los datos recolectados, acerca del tema en estudio. El mismo está dividido en tres partes:

_ Relación afectiva docente y estudiantes.

_ Tipo de comunicación: lenguaje verbal y gestos empleados por la docente G.

_ Nivel de participación que se fomenta.

\section{Segunda parte}

\section{Referente teórico}

\section{“El tacto pedagógico" en las relaciones entre el docente y los estudiantes.}

Conviene que las relaciones que el grupo de estudiantes desarrolla con las y los docentes, sean seguras y afectuosas. Estos lazos se van fortaleciendo diariamente, con la guía del maestro y la seguridad emocional que éste les pueda dar. 
El docente juega entonces un papel fundamental en la vida de la y el estudiante, pues por una parte, es el encargado de facilitar el aprendizaje, pero también se espera que provea a la niña y al niño de seguridad emocional, lo conduzca o guíe y atienda la diversidad, en cuanto a comportamientos. Al respecto Ringness (citado por Zúñiga, 1997, p. 66) argumenta que "el maestro es quien establece el clima emocional a través de sus actitudes y la forma en que conduzca las actividades".

Ese ambiente emocional que se genera en las aulas, producto de las interacciones personales, puede marcar pautas positivas en pro de la participación más fluida del estudiantado, así como la demostración de una amplia gama de sentimientos. Para lograr este cometido, conviene que los docentes establezcan una relación de empatía, donde el afecto, la confianza, el respeto, el diálogo y la comprensión estén siempre presentes, con el fin de crear un ambiente positivo basado en el afecto y la autoridad.

Van Manen (1998) explica lo importante que es para los educadores, tener tacto en las interrelaciones con sus estudiantes. Para él, el tacto implica una gran sensibilidad y una percepción consciente que debe procurar, en este caso, el educador, con la y el estudiante; como bien los señala éste, "...una persona que tiene tacto posee la habilidad de saber interpretar los pensamientos, las interpretaciones, los sentimientos y los deseos interiores a través de claves indirectas como son los gestos, el comportamiento, la expresión y el lenguaje corporal" (1998, p. 137).

Cuando el docente es muy respetuoso, reflexivo, considerado, sensible, perceptivo, discreto, cortés y cariñoso, el tacto pedagógico marcará la diferencia entre las relaciones con los educandos, pues asume la responsabilidad de proteger, educar y ayudar a las y los estudiantes a "madurar psicológicamente".

Van Manen (1998) señala que con el tacto pedagógico, se persigue que en la relación entre docente y estudiante se logre:

a- Proteger lo que es vulnerable. Permite al docente resaltar las cualidades que posee la niña y el niño.

b- Aprender a sobrellevar el dolor.

c- Permitir a la niña y al niño momentos para la toma de decisiones. El adulto fomenta espacios donde el estudiante pueda tomar decisiones y actuar por sí mismo. Para ello resulta fundamental desarrollar una relación comunicativa equilibrada.

d- Reforzar lo que es bueno. Es fundamental que el educador desarrolle mediante la incentivación, las singularidades de sus estudiantes: actitudes, habilidades y destrezas. 
e- Favorecer el crecimiento personal y el aprendizaje. Permite percatarse de los errores o fallas que tienen las y los estudiantes para guiarlos y orientarlos a la corrección, realimentación y autoevaluación.

El tacto pedagógico logra estos propósitos por medio de un ambiente positivo donde se trabaja con el silencio, la palabra, con la mirada, el gesto, el ejemplo y el ambiente. Por eso resulta muy positivo que el docente tome en cuenta estos aspectos en el desarrollo de las relaciones con sus estudiantes.

El tacto pedagógico permite el aprovechamiento de habilidades que pueden ser consideradas, verdaderos y significativos procesos de enseñanza y aprendizaje, así como el desarrollo de profundas y significativas relaciones interpersonales en el salón de clases.

Como bien lo señala Van Manen (1998), el tacto pedagógico proporcionará al proceso educativo:

- Realizar maravillas y dejar huella en la y el estudiante.

- Plantear que lo difícil resulte fácil.

- Preocupación por el interés del estudiante.

- Creación de nuevas posibilidades

\section{3- Tercera parte}

\section{El tacto pedagógico en el salón de clases}

\section{Caso específico: la sala de clases de la docente $\mathbf{G}$}

Para el caso que interesa y tomando en cuenta las categorías ya indicadas, se presenta la interpretación de los datos obtenidos producto de la observación no participante y otros recursos: dibujos, entrevistas llevadas a cabo en el primer grado de la maestra G.

\section{A- Respecto a la relación afectiva docente y estudiantes.}

Se pudo constatar que, en este salón de clases, las manifestaciones de cariño, tanto de la docente hacia los niños, como de éstos hacia ella, están siempre presentes en sus interrelaciones. Las muestras de afecto de la docente $G$ hacia sus estudiantes, son tanto verbales como no verbales.

En las lecciones observadas, se constató que la comunicación verbal de la docente $G$ y estudiantes es usada, entre otras cosas, para compartir afecto, así como para realizar las llamadas de atención necesarias para corregir a los estudiantes y lograr así una formación integral de los mismos. Las siguientes frases que se presentan, dejan ver el tipo de comunicación verbal que se implementa en este salón de clases: 
“... Preciosa, jte está quedando muy bien el trabajo!”.

“... Mi amor iqué bien estás trabajando!”.

Asimismo, no falta por supuesto el abrazo y la caricia de la docente hacia los estudiantes, como manifestaciones afectivas hacia éstos. Estas manifestaciones tal y como lo señala (Restrepo, 1999, p.12) son fundamentales “... la caricia es fundamental, la caricia es humanizadora". Al respecto, León (1998, p. 66) aduce que "sentirse querido en el aula implica, por tanto, sentirse aceptado y cómodo en sus relaciones con la maestra y con los compañeros".

Las relaciones que se suscitan entre docentes y estudiantes, pueden favorecer o afectar la percepción y la autoestima que este último tiene de sí mismo; estos aspectos van a influir en el proceso de aprendizaje que se lleva a cabo en un salón de clases. Al respecto, Slavin (1995, p. 65) afirma que "es esencial que los alumnos estén convencidos de que son personas valiosas e importantes para que puedan tolerar las desilusiones de la vida, tomar decisiones con confianza y, finalmente, ser felices y productivos".

Para el niño resulta fundamental sentirse querido, aceptado y cómodo en sus relaciones con la docente. Estos aspectos se reflejan en la percepción de la imagen que los estudiantes poseen de la maestra que comparte y desarrolla un proceso cotidiano de aprendizaje y enseñanza.

El aspecto afectivo presente en los salones de clase, es un factor muy valioso, tanto para las relaciones interpersonales que entre ellos se suscitan, como para el desarrollo de un proceso de enseñanza y aprendizaje que resulte interesante y motivador, para las y los niños y para el docente.

La empatía que surge y va desarrollándose entre docente y estudiantes, resulta ser clave para que se dé una excelente relación pedagógica. Van Manen (1998, p. 80) al respecto manifiesta que "el amor pedagógico del educador para con estos niños se convierte en la condición previa para que exista la relación pedagógica".

En las lecciones de la docente $G$, las relaciones interpersonales están marcadas por un ambiente de amistad, respeto, comprensión, escucha y mucho cariño; aspectos que, sin duda alguna, aumentan la autoestima y el sentido de pertenencia de la y del niño. Estas necesidades resultan ser fundamentales durante la edad escolar, pues en esta etapa, las relaciones interpersonales alcanzan un gran valor en el desarrollo socio emocional de la niña y del niño.

Como producto de este aprecio y de la admiración que las y los niños sienten por su maestra, generalmente ellos tienen una percepción idealizada hacia ella. 
Las niñas y niños encuestados la detallan así:

“... Mi maestra escribe lindo, fichas lindas, es muy linda y muy buena". (Jonathan)

“... La niña G es muy bonita y buena, es como mi mamá". (Cristel )

La psicología ha sido de gran ayuda en los procesos educativos que se desarrollan en las instituciones educativas. Entre los procesos que se han dado a la tarea de investigar, se encuentra el análisis del dibujo de la figura humana. Este aspecto, para efectos de este estudio, nos proporciona un instrumento útil para tratar de determinar, la percepción que la niña y el niño tienen de los adultos que lo rodean y, en el caso específico que nos compete, la imagen que tiene de la docente. Con el análisis de la expresión pictórica y gráfica del dibujo que hacen las y los niños y las y los jóvenes de la figura humana, se pretenden valorar aspectos intelectuales, emocionales y de maduración. El dibujo de la figura humana, como bien los señala Esquivel y otras (1999), es una expresión, una comunicación muda. Al respecto las mismas autoras aducen que, “... dibujar es expresar con marcas, imágenes $u$ otros signos, lo que a veces no se puede decir con palabras. El dibujo tiene entonces, también una función de comunicación" (Esquivel, 1999, p. 172).

La niña y el niño al dibujar están dejando impreso en la imagen, una serie de asociaciones tanto intelectuales como afectivas, las cuales son producto de su experiencia personal.

Resulta entonces muy importante rescatar los mensajes que llevan implícitos los dibujos que los niños realizaron de su maestra.

En las figuras que se presentan, se pueden apreciar algunos detalles de la percepción que los niños tienen de su maestra. Los dibujos muestran la figura de una docente que aparece con los brazos abiertos, y muy sonriente. Tal y como lo señala Esquivel y otras (1999) el niño y la niña al dibujar, da indicios de valorización de un personaje, cuando éste dibuja primero al personaje que considera más importante, al que admira. Argumentan las autoras también que, "otro signo de valorización, es el aumento de tamaño de algunos de los elementos o personajes" (1999, p. 219)

Un aspecto importante para tomar en cuenta, es el espacio que ocupa y el tamaño del docente en el dibujo. Estos aspectos nos indican la valoración del que dibuja hacia el personaje. En el caso de los estudiantes de la docente $G$, se puede observar que existe un nivel de valoración de su maestra; en sus dibujos se evidencia un elemento central esencial: la docente, así como el aumento de ciertas partes del dibujo: brazos y rostro. 

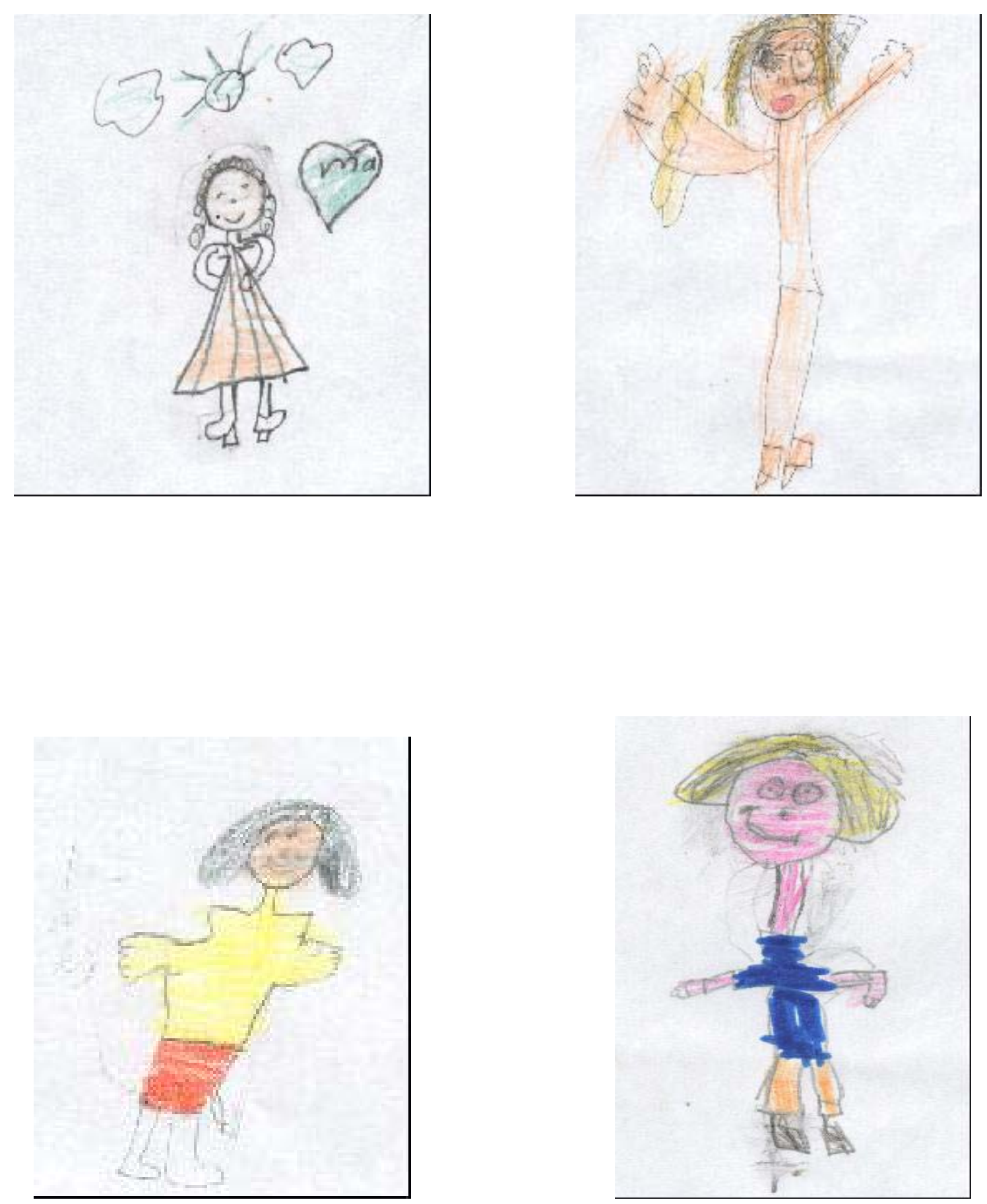
En la figura que, a continuación se presenta, se puede deducir cómo el niño y la niña visualiza a su maestra, como aquella persona que tiene mucho trabajo por cumplir (obsérvese la cantidad de cuadernos por revisar que hay sobre su escritorio). Sin embargo, está ahí atendiendo a él, a sus compañeros y compañeras de manera individual. Para Esquivel (1999), la distancia física entre los personajes de un dibujo y el plano en que se representan, reflejan la distancia emocional y el grado de comunicación existente entre ellos. Como bien se observa, en este dibujo, ambas características están presentes en la relación docente y estudiante, pues como se puede visualizar, se presenta una docente muy cercana al niño y la niña.

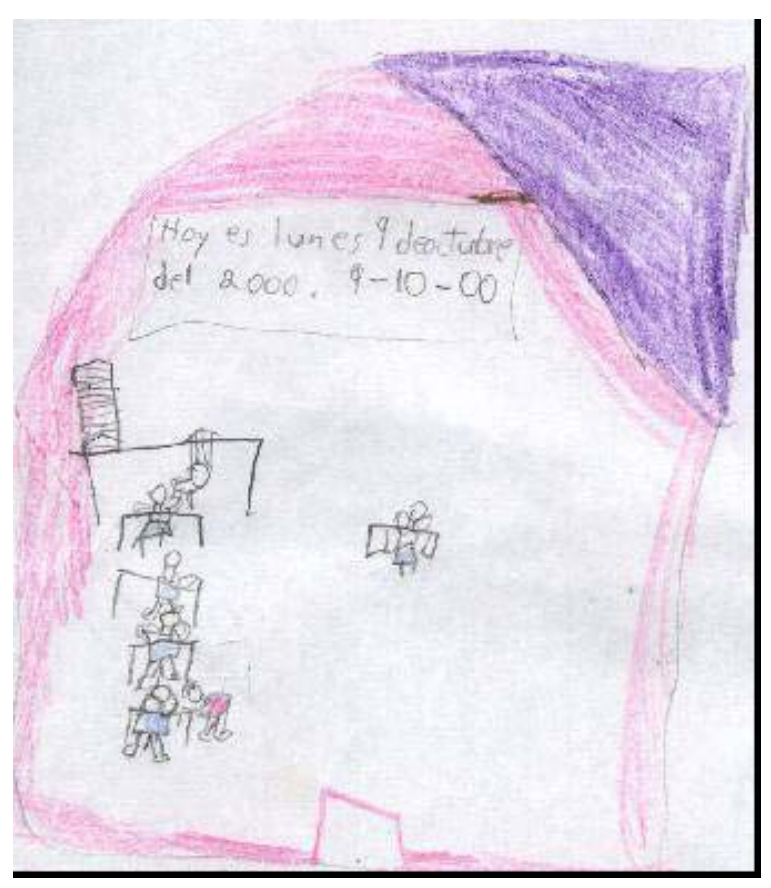

Al interrogar a la docente acerca de si, ¿está satisfecha con la profesión que eligió?, su respuesta fue:

“.... Por supuesto, es lo mejor que pude haber hecho, a pesar de lo cansado. A pesar de todas las desventajas que existen". (Docente $G$ )

También, se le interrogó con respecto a:

- ¿Qué aspecto resulta crucial en las relaciones interpersonales con los estudiantes? La docente contestó: ....."El amor que se les demuestre. La confianza que les brinde".

Por la respuesta positiva de los niños y niñas ante las diferentes actividades de mediación desarrolladas en las lecciones, es factible determinar que el amor y gusto por la 
profesión, resultan ser una fórmula eficaz, para lograr que el estudiante mantenga un óptimo estado emocional y su disposición a aprender. León (1998, p. 55) manifiesta que:

... El gusto por trabajar con los niños es un componente muy importante del trabajo de cualquier maestro o maestra, pero, además de disfrutarlo, requiere capacidad profesional no solamente en el plano del aprendizaje sino también en el abordaje de sus necesidades socio emocionales.

Cuando el educador se identifica con su profesión, esto contribuye a lograr un proceso educativo, acorde con las necesidades cotidianas que se suscitan en los salones de clase. El contacto diario del educador y el grupo de educandos, hace que a pesar de las desventajas, como lo señala la docente entrevistada, si hay mucho afecto y se le corrige en el momento oportuno, resulta fácil acoger a las niñas y a los niños.

Así, un docente debe procurar generar un buen clima emocional y esto lo logra, cuando es cariñoso, comprensivo y comunicativo.

\section{B- Tipo de comunicación: lenguaje verbal y gestos empleados por la docente.}

La comunicación es un proceso fundamental en el desarrollo de las relaciones interpersonales que se dan entre los seres humanos. En el nivel del salón de clases, la comunicación es indispensable para lograr un excelente desarrollo, tanto de las relaciones interpersonales, como del proceso educativo.

Medina manifiesta que,

... la interacción en la enseñanza es un proceso comunicativo-formativo, caracterizado por la bidireccionalidad, reciprocidad de los agentes participantes en ella. La interacción se incorpora a la enseñanza, siendo más que una comunicación o influencia mutua una fuerza cohesionadora que hace eficiente el proceso de enseñanza-aprendizaje, en cuanto sirve al alumno para adquirir una formación intelectual y actitudinal. $(1989$, p. 31)

En el proceso de comunicación que se implementa en un salón de clases, está presente una serie de aspectos como: creencias, conocimientos, formas de concebir el mundo, tanto de los docentes como de las y los estudiantes, los cuales deben ser tomados muy en cuenta, al desarrollar el proceso educativo. Para Picado (2001), ser un buen educador es ser un buen comunicador, para provocar en el alumno, el deseo de aprender. La misma autora señala que, "el objetivo principal de la comunicación es ayudar al 
estudiante a conocerse, aceptarse y autogobernarse. Una comunicación eficiente influye favorablemente en la autoestima del educando" (Picado, 2001, p. 29).

En los salones de clase, es preciso que sea compartida la participación de los sujetos, docentes y estudiantes. Sólo así, el proceso de aprendizaje será desarrollado como un proceso de interacción que permita la plena realización de cada estudiante, y ésta se logrará a través del estímulo del aprender a conocer; aprender a vivir juntos; aprender a hacer y aprender a ser.

Para el logro de estos fines, es preciso contar con docentes, que al igual que la docente $G$, implementen en sus salones de clase, actividades que favorezcan la comunicación horizontal docente- estudiante y estudiante - estudiante. En las lecciones observadas, se pudo constatar el empleo por parte de la docente $G$ de actividades, como: exposiciones de las y los niños de sus trabajos, demostraciones por parte de la docente, trabajos en subgrupos, conversaciones en círculo y otros.

Asimismo, en el cotidiano vivir del salón de clases, la comunicación puede convertirse en un proceso, que procure también impulsar principios y valores, que permitan el desarrollo personal y social de cada una de los y las estudiantes. La docente debe procurar aprovechar las circunstancias que se presenten para favorecer los valores. En el caso en estudio, la docente aprovechó una situación que se presentó para fortalecer el valor del respeto, pues la educadora insiste en recalcar que todos tienen diferentes formas de aprender. En esta ocasión; se evidenció una llamada de atención que reafirmó lo anteriormente expuesto. Así, en una de las lecciones de matemáticas, a Carolina le cuesta la lectura de números de dos en dos; de pronto un niño se burla, por lo que la maestra le dice: “...Nadie tiene por qué reírse; cualquiera se equivoca. Si nos equivocamos y se burlan de nosotros, más mal nos vamos a sentir". Ante este tipo de situaciones el niño y la niña necesitan sentirse aceptados y protegidos en momentos que provocan tensión. En situaciones como ésta, Carolina requiere saber que cuenta con una docente que sabe controlar de manera eficiente la situación.

Otro aspecto importante por destacar en las relaciones interpersonales que se suscitan en este salón de clases, en cuanto a la comunicación verbal de la maestra con los estudiantes, es el empleo constante de la identificación del género al referirse a los niños y niñas.

En la interacción comunicativa del proceso de enseñanza, se señalan básicamente dos tipos o maneras de comunicarse: el énfasis en lo verbal y el énfasis en lo no verbal (gestos). 
Como bien lo señala la Fundación PANIAMOR (1999, p. 60) es importante tomar en cuenta que se logra un equilibrio entre ambos tipos de comunicación, cuando "las cosas se dicen directamente, se habla en forma clara y firme, y el mensaje que se da es congruente con la expresión facial, la posición del cuerpo y el tono de voz".

Ambos tipos de comunicación se pusieron en evidencia en el salón de clases de la docente G. En la primera sesión de trabajo que se observó, los niños venían ingresando del recreo. Éstos hacían mucho ruido y entonces la maestra con voz muy suave dijo:

"Vamos a tranquilizarnos y cuenta uno, dos y tres, a trabajar tranquilos con amor y cuenta uno dos y tres". Las niñas y los niños inmediatamente colocaron sus brazos y cabeza en posición de reposo y luego volvieron a la posición normal. Ante esta situación, la maestra cumple un rol muy importante en la interacción social, al marcar un hito en la dirección de la clase y el control de la situación y de los valores que se suscitan en el proceso educativo.

En el proceso de aprendizaje, resulta muy importante el papel que juega la comunicación asertiva. Al respecto la Fundación PANIAMOR (1996, p. 73) manifiesta que para que exista este tipo de comunicación, es preciso,

ser congruente entre lo que sentimos, pensamos, decimos y hacemos, en forma abierta, clara y sincera. También implica el escuchar con atención lo que la otra persona dice y respetarla en su singularidad; no verla a través de nuestros esquemas mentales, sino en sí misma.

A través de este tipo de comunicación, la docente les comunica a los estudiantes que son importantes para ella. Un docente asertivo es aquel que establece procesos comunicativos caracterizados por diálogos, donde al hablar mira a los ojos a las y los estudiantes; se dirige a ellos por su nombre y, si es necesario, da muestras corporales de estima. Estos procesos de comunicación asertiva, se pudieron observar en las interrelaciones de la docente $G$ y sus estudiantes. Se presentan, a continuación, algunos momentos vividos en el salón de clases y que ejemplifican estos procesos asertivos.

..."eso es mi amor, muy bien va su trabajo".

..."ve qué bien papito, usted ya va a terminar".

En todas las sesiones que se observaron, es importante recalcar que la docente no necesitó en ningún momento alzar el tono de voz.

La docente $G$ expresa otros sentimientos: de aprobación, admiración y afirmación a través de gestos, miradas, sonrisas, las cuales resultan ser un complemento en el proceso de comunicación docente y estudiantes. 
Como bien lo señala Van Manen (1998, p.188) "el gesto corporal es una especie de lenguaje que puede infundir significado e importancia a una situación determinada".

\section{C- Nivel de participación que se fomenta}

En cuanto a la participación que se fomenta en el ambiente de un salón de clases, ésta debe procurar que, tanto el docente como sus estudiantes, tengan oportunidad de participar.

Para ello es preciso implementar estrategias de enseñanza y aprendizaje que procuren procesos constructivos, donde el estudiante sea el propio constructor de su conocimiento, el cual, por ende, va a resultar, significativo. Tal y como menciona Molina (1997, p. 135) el aprendizaje significativo "implica partir de la realidad del alumno e impulsarlo a desarrollar su potencial de aprendizaje". Ahora bien, para alcanzar este tipo de proceso educativo, es preciso que se implementen momentos y metodologías que promuevan una participación horizontal de todos los participantes.

Es preciso que el docente fomente la participación constante de las y los educandos en los procesos de aprendizaje. Cuando el estudiante tiene la oportunidad de construir con la guía y orientación del docente, los conocimientos, el aprendizaje además de verdadero, se tornará significativo. Para que la y el estudiante logre este objetivo, es preciso que sea motivado extrínsecamente. Molina (1997) manifiesta que para alcanzar este tipo de motivación, es necesario implementar actividades que estimulen la creatividad, tareas escolares que sean significativas y con un nivel óptimo de dificultad, el grado de autonomía que se suscite y el fomento de aprendizaje cooperativo.

En el salón de clases de la docente $G$, algunos de estos aspectos fueron evidenciados durante las observaciones realizadas.

En una de las lecciones de Ciencias, la docente organiza una olimpiada de preguntas. En esta actividad la docente divide el grupo en dos, comienza a realizar preguntas a cada grupo de manera que por cada pregunta que se conteste bien, el grupo obtiene un punto. Cuando finalizan las preguntas, la docente junto con las y los niños cuentan la cantidad de puntos que tiene cada uno, gana el grupo que más puntos tenga a favor.

Todos los niños y las niñas desean participar; algunos están molestos porque ya unos participaron y están volviendo a participar. Entonces un grupo le dice a la docente: "Niña sólo escoge a los que no saben”. La maestra responde: “¿Cómo que no saben? Vean que bien lo han hecho los que han venido". 
En este salón de clases, el nivel de participación docente-estudiantes resulta muy balanceado. La docente $\mathrm{G}$ guía muy bien sus lecciones; hace participar al máximo a sus estudiantes a través de técnicas como la interrogativa, la resolución de ejercicios orales, dinámicas grupales, trabajos grupales, y otros. Este tipo de actividades de enseñanza y aprendizaje, permite el desarrollo de potencialidades como el autoaprendizaje y el desarrollo del pensamiento crítico y creativo, así como el de competencias valiosas para la vida.

A continuación, se anotan algunos ejemplos del proceso de participación que se fomenta en este salón de clases.

En la lección de Español, la docente le solicita a Jonathan que lea las oraciones que él construyó. Jonathan lee en voz alta sus oraciones, mientras que las y los compañeros y la docente lo escuchan atentamente.

En la clase de Matemáticas, la docente procura que las y los niños realicen la lectura de los números de dos en dos, de tres en tres hasta cincuenta. Los y las niñas repiten oralmente. De pronto la maestra dice: "hay voces que casi no las oí. Vamos a empezar de nuevo". Las y los niños participan de manera muy entusiasmada.

La docente pregunta: “¿Quién viene a la pizarra a escribir el nombre de estos números?” Todos los niños y las niñas quieren ir a la pizarra.

En una lección de Ciencias, la docente divide el grupo en dos para competir y comienza a realizar preguntas orales acerca del lugar donde viven los animales. Todos los niños y las niñas levantan las manos, porque quieren participar muy activamente en las preguntas que formula la docente. Algunos niños y niñas interesadas alzan la voz diciendo: "Niña a mí, niña a mí". La docente va dando la palabra uno a uno. Ante la posibilidad de participación que les da su maestra, las y los niños se observan muy complacidos con este tipo de actividades.

Otro aspecto que conviene rescatar, es el adecuado uso que la docente hace del espacio físico, específicamente en cuanto a la colocación del mobiliario: en hileras, en parejas y grupos. Este tipo de organización, obedece al empleo variado de técnicas, las cuales hacen posible que el nivel de participación de las y los estudiantes en el proceso lectivo se incremente. Tal y como lo señala (Campos, 1993, p. 90): "es importante que el maestro cambie la distribución de pupitres, pues este cambio en sí puede generar interés en los niños, se rompe la monotonía y se establecen interacciones con diferentes niños del aula". En el caso específico de la docente G no existe una única forma de distribuir a las y los estudiantes y los pupitres en el aula. Realmente ella no conserva estática la distribución 
espacial en su salón de clases, sino que por el contrario, ésta obedece a las actividades de aprendizaje que pretende impulsar.

En una de las lecciones, la maestra colocó a las y los niños en hileras pero en parejas y les manifestó lo siguiente: "cuando nos sentamos así, es para compartir conocimientos". En una de las lecciones de Estudios Sociales, los y las niñas en grupos realizan un trabajo, donde deben consultar una guía, contestarla y realizar unos dibujos. En uno de los subgrupos, algunas niñas y niños estaban molestos, porque sus compañeros y compañeras no les permitían leer la hoja guía. La docente $G$ se acerca a las y los niños; los mira; mueve su cabeza en señal de desaprobación y les expresa. "¿Qué pasa aquí? el trabajo de grupos es para compartir". Entonces las y los niños pasan rápidamente la hoja a los compañeros que se quejaban y siguen trabajando.

Este tipo de actividades procuran alcanzar la doble faceta del proceso de aprendizaje: la individual y la social. Resulta muy importante para la y el estudiante que el proceso de enseñanza y aprendizaje procure su propio aprendizaje; pero también es muy necesario que el proceso brinde la posibilidad a las y los estudiantes de realizar trabajos colectivos que les permitan desarrollar conocimientos, valores, competencias y otros. Tal y como lo señala Slavin (1995, p. 74): "el aprendizaje cooperativo aumenta el contacto entre los alumnos, les brinda una base compartida de semejanzas (la pertenencia a un grupo), los involucra en actividades conjuntas agradables y los hace trabajar por un objetivo común". Este tipo de aprendizaje pretende que las y los estudiantes compartan experiencias de enseñanza y aprendizaje, que permita entre todos, construir el conocimiento, aprendiendo unos de otros. La interacción estudiante- estudiante y de ellos y ellas con el docente, fomenta el desarrollo de un aprendizaje crítico y creativo en equipo.

La comunicación no verbal, es un aspecto fundamental en un proceso de enseñanza y aprendizaje. En el salón de la docente $\mathrm{G}$ este tipo de comunicación se manifiesta de manera constante, ella resulta ser una docente muy expresiva, sus gestos refuerzan el respecto y el cariño que les da a sus estudiantes. Al respeto Medina (1989, p. 36) aduce que,

La conducta no verbal es el reflejo, casi literal, de la expresión más coherente del sujeto, no sólo se simbolizan, sino que se expresa lo más profundo de nosotros mismos a través de la piel la conducta no verbal (gestos, movimientos, coloración de la piel).

Por medio de gestos, el o la docente obtiene grandes logros en la comunicación con sus estudiantes. 
Otro aspecto que resulta importante destacar, es el tipo de estímulo que recibe el y la estudiante, posterior a su participación en las actividades de aprendizaje. La docente G se encarga siempre de hacer sentir muy bien a la niña y al niño que participa. Siempre hay un elogio, una felicitación, una sonrisa o una caricia. $Y$ para los que no participan, también existe un estímulo verbal para que, en algún momento, externen sus ideas y opiniones. Por ejemplo, en una clase de matemáticas, un niño lee los números que la maestra le indica y, una vez que el niño termina su labor, hay para él una gran sonrisa y la siguiente frase: "Muy bien, muy bien".

La docente solicita a otro niño que mencione los números de 5 en 5 hasta 95, la maestra al terminar le dice: “¡Excelente!” $Y$ se vuelve al grupo y les manifiesta: "muy bien, ¡qué bien que lo están haciendo!"

En síntesis, las interacciones personales entre docentes y estudiantes marcan un hito muy importante en los procesos de enseñanza y aprendizaje. El desarrollo fluido de los procesos de comunicación asertiva, caracterizados por el respeto, la comprensión, el diálogo y un buen manejo de límites, hacen que el proceso educativo que se desarrolle en un salón de clases, conduzca a la formación integral de las y los estudiantes.

La docente $\mathrm{G}$ tiene una amplia experiencia laboral en el ámbito educativo de la región. Este aspecto le ha permitido laborar en los diferentes niveles de la Educación General Básica. La permanencia en el trabajo con niños y niñas de diferentes edades y "estilos de aprendizaje", permite afirmar que la actitud que asume esta maestra para orientar el proceso educativo que desarrolla con las y los estudiantes, es idónea. Por tanto, las relaciones interpersonales que se suscitan en el salón de clases de esta docente, tienen como prioridad el logro de los objetivos propuestos, tanto de índole académico, como afectivo.

\section{4- Cuarta parte Conclusiones}

En cuanto a la relación afectiva docente y estudiantes:

1- La relación afectiva que se suscita entre la docente $G$ y sus estudiantes está caracterizada por el desarrollo y la permanencia de relaciones interpersonales, basadas en el respeto y la apertura de espacios que son aprovechados por los niños y niñas, para llevar a cabo un aprendizaje más significativo.

2- El clima emocional que se observa en el salón de clases facilitó la comunicación verbal y no verbal, permitiendo con ello, que el proceso comunicativo se torne participativo, aspecto que va a permitir un proceso de enseñanza y aprendizaje eficiente. 
3- El o la docente juega un papel protagónico en el desarrollo de un clima emocional, que favorezca el crecimiento personal de los y las estudiantes, así como del proceso de un aprendizaje significativo.

4- El tacto pedagógico permite el desarrollo de interacciones personales, que faciliten el proceso de aprendizaje, así como el establecimiento de relaciones de empatía, que coadyuven en la creación de un ambiente escolar positivo, basado en el afecto y la autoridad.

En cuanto al tipo de comunicación verbal y no verbal empleada por la docente en su relación con los y las niñas:

1- El proceso de enseñanza y aprendizaje que implementa la docente $G$, facilita un proceso comunicativo horizontal, pues la mediación pedagógica que impulsa, procura el desarrollo de variadas formas de participación, tanto individuales como cooperativas, las cuales facilitan la construcción de un conocimiento significativo.

2- Un ambiente emocional que provea al estudiante de seguridad emocional, afecto, confianza, respeto y comprensión; genera una participación más fluida de los y las estudiantes en los procesos de enseñanza y aprendizaje.

3- En el desarrollo de un proceso educativo que favorezca la inclusión, resulta fundamental que en el proceso de comunicación, el o la docente empleé continuamente la identificación del género al referirse a los y las niñas.

4- En la interacción comunicativa que se desarrolla en el proceso de enseñanza y aprendizaje, es indispensable que el o la docente enfatice en el empleo de la comunicación verbal y no verbal.

5- La docente G emplea continuamente la comunicación asertiva, proceso que permite que en el salón de clases de esta educadora, los niños y las niñas sean respetados y escuchados continuamente.

En relación con el nivel de participación que fomenta la docente con los y las estudiantes:

1- El estímulo e incentivación que reciben las y los niños, cuando participan en las diferentes actividades de mediación que implementa la docente $G$, hacen que éstos se sientan seguros, comprendidos y alentados para volver a participar.

2- Mediante procesos de evaluación diagnóstica y formativa, es posible darse cuenta de que la respuesta de las y los niños ante los procesos educativos que se llevan a cabo, 
están estrechamente relacionados con la forma y orientación que le "imprime" la docente a las lecciones.

3- La participación constante de los y las estudiantes en los procesos de aprendizaje que desarrolla la docente $\mathrm{G}$, permiten la construcción del conocimiento, así como el estímulo de procesos creativos en las actividades escolares que se ejecutan en el salón de clases.

4- Los procesos de enseñanza y aprendizaje que se implementaron en el salón de clases observado, permitieron el desarrollo individual y grupal de los y las estudiantes, los cuales impulsaron la puesta en marcha de una acción educativa creativa, constructiva y socializante.

5- Es de suma importancia que el personal docente que labora en el sistema educativo costarricense, se de a la tarea de impulsar el desarrollo de un clima motivacional adecuado, que permita por un lado, el aprovechamiento de las habilidades y destrezas de los y las estudiantes, para el logro de procesos de enseñanza y aprendizaje significativos, y por otro lado, procuren el desarrollo de profundas y significativas relaciones interpersonales.

\section{Referencias}

Campos, Saborío Natalia y otras. (1993). Conocimiento, participación y cambio: espacio en el aula. San José, Costa Rica: Editorial Universidad de Costa Rica.

Esquivel, Fayne, Cristina Heredia, Emilia Lucio. (1999). Psicodiagnóstico clínico del niño. México: Editorial El manual moderno.

León, Ana Teresa. (2001). El maestro y los niños: la humanización del aula. San José, Costa Rica: Editorial Universidad de Costa Rica.

Medina, A. (1989). Didáctica e interacción en el aula. Colombia: Cincel Kapelusz.

Molina, Bogantes Zaida. (1997). Planeamiento didáctico. Fundamentos, principios, Estrategias y procedimientos para su desarrollo. San José, Costa Rica: EUNED.

Fundación PANIAMOR, Programa A.M.O.R. (1996). Autoestima y comunicación en las Relaciones intergeneracionales. San José, Costa Rica: PANIAMOR.

Picado, Godínez Flor María. (2001). Didáctica general. Una perspectiva integradora. San José, Costa Rica: EUNED.

Restrepo, Luis Carlos. (1999). La pedagogía de la ternura. Conferencia magistral en el I Congreso Internacional de Educación Primaria realizado por la Escuela de Formación Docente de la Facultad de Educación U.C.R. 
Slavin, Robert E. (1999). Aprendizaje cooperativo. Teoría, investigación y práctica. Buenos Aires, Argentina: Aique.

Vásquez, y Martínez, I. (1996). La socialización en la escuela. Una perspectiva Etnográfica. Barcelona, España: Paidós.

Van Manen, M. (1998). El tacto en la enseñanza. El significado de la sensibilidad pedagógica. Barcelona, España: Paidós.

Woods, Meter. (1993). La escuela por dentro. La etnografía de la investigación educativa. Barcelona, España: Paidós.

Zúñiga, I. (1996). La percepción idealizada de la maestra, su conocimiento y sabiduría en las relaciones interpersonales maestro-niño de una escuela pública del Área Metropolitana de San José. Imágenes. 3 (6): 59-70.

Zúñiga, I. (1997). Relación afectiva maestra-niño; autorrealización y percepción acerca del grupo en el ámbito de las relaciones interpersonales en una escuela pública del Área Metropolitana de San José. Imágenes. 4 (7): 65-77. 